\title{
Study of the Seroprevalence of Anti-Leptospirosis Antibodies in Subjects in Two Districts (Lamordé and Koira Tégui) and at the Cold Slaughterhouse of Niamey
}

Lewamy Mamadou ${ }^{1}$, Seini Habiboulahi ${ }^{1}$, Sani Ousmane ${ }^{2}$, Bakasso Sahabi ${ }^{1}$, Chaibou Yaou ${ }^{1}$,

Haoua Sabo ${ }^{1,2} \&$ Hassimi Sadou ${ }^{1}$

${ }^{I}$ Department of Chemistry, Faculty of Science and Technology, Abdou Moumouni University,

BP 10662, Niamey, Niger. ${ }^{2}$ CERMES, Niamey, Niger.

Crossref

DOI: http://doi.org/10.38177/ajast.2021.5411

Copyright: () 2021 Lewamy Mamadou et al. This is an open access article distributed under the terms of the Creative Commons Attribution License, which permits unrestricted use, distribution, and reproduction in any medium, provided the original author and source are credited.

\section{ABSTRACT}

Leptospirosis is a tropical and subtropical zoonotic disease culminating as a serious public health problem worldwide, apparently existing as co-infections with various other unrelated diseases, such as malaria. It is caused by spiral bacteria and the main vectors of which are rodents. These bacteria have various survival mechanisms in the environment allowing them to carry out their infectious cycle within their host organisms. The pathophysiological mechanisms pertaining to leptospirosis is still not understood in full and mis or underdiagnosed.

A cross-sectional descriptive study was carried out in three different localities in Niamey where respondents were screened for to demonstrate transmission to humans. Indirect ELISA method as a laboratory diagnostic or screening toll is used by utilizing leptospiral-specific IgG from serum samples of the respondents.

Results from the study showed that 11 people are found to be positive for leptospirosis (with a seroprevalence of $2.75 \%$ ) with a strong tendency in the slaughterhouse workers which presents a fairly high risk compared to the other localities of the study. Indeed, the different areas/localities of this pilot study do not present the same level of risk because they are not subject to the same risk associated factors. In this vein, we have $87.6 \%$ of population exposed to the presence of rats, $48 \%$ are in contact with animals, $38.6 \%$ live in homes near water and $12.9 \%$ go swimming.

This study made it possible, on the one hand, to highlight the transmission of leptospirosis from animals to humans and, on the other hand, to draw attention to the involvement of the various identified risk factors.

Keywords: Antileptospirosis Ab, Seroprevalence, ELISA test.

\section{Introduction}

Leptospirosis is a globally distributed zoonosis caused by spiral bacteria called leptospira. It is a disease endemic to tropical climates and, which more particularly affects disadvantaged rural and peri-rural areas (Picardeau 2015b). Rodents, especially rats, are major reservoirs of these leptospira: the bacteria reside in the renal tubules of their hosts and are excreted into the environment via their urine. Leptospirosis is generally considered to be a water-related disease where humans and livestock become infected through contact between the pathogen and their mucous membranes or skin lesions (Levett 2001). The leptospira responsible for leptospirosis belong to the order of Spirochaetes, family Leptospiraceae, genus Leptospira (Martel 2019). They are the smallest of the spirochetes, their name comes from the Greek "leptos" and "spira" meaning end, hail and whorl, tower (Cameron 2015). These bacteria have developed various survival mechanisms in the environment and, through their infectious cycle, which includes entering the host, escape the immune response, adhere and colonize the tissues; then exit the host to initiate a new infection. Different constituents play a role in the virulence of bacteria. It should be noted that the mechanisms and factors of virulence of leptospira are mysteries on which many studies have been carried out in order to improve the diagnostic tools of the disease, and to develop new vaccines, etc. (Liegeon et al. 2018). However, the biological confirmation of leptospirosis, according to the WHO, is based on the isolation of the bacteria or the identification of its nucleic acids in biological samples, or on a positive serology in a suggestive clinical and epidemiological context (WHO, 2011). Serology is the most common test to diagnose leptospirosis. 


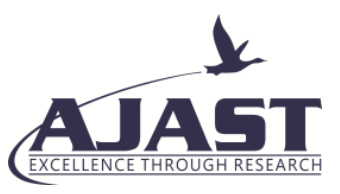

Asian Journal of Applied Science and Technology (AJAST)

Volume 5, Issue 4, Pages 93-108, Oct-Dec 2021

The most recent global incidence assessment reports an estimated 1.03 million cases annually, for an average incidence rate of 14 cases per 100,000 population and a mortality of 7\% (Costa et al. 2015). It is likely that these figures are underestimated due to a lack of information in certain areas of the world where the means of diagnosis are very limited. The most vulnerable group are men (80\% of the time) and half of them in the 20-50 age group (Raffray 2017). It is a relatively unrecognized and underdiagnosed disease in many countries, especially in Africa. In the Sahel, for example, there are only a handful of data on leptospirosis, including two studies in humans and cattle carried out in the 1970s in Senegal, a case detected in a dog in 2008 and a human case reported in the 1990s in Chad, and a livestock study in the early 1970s in Mali (Vries et al. 2014; Allan et al. 2015a).

The research paper, the first one undertaken in Niger, intends to assess the hypothesis that leptospirosis exists in Niamey. We thus undertook a case study of two districts of Niamey namely Lamordé and Koira tégui as well as the modern animal slaughterhouse, areas of completely different sociodemographic transmission environments of leptospirosis from animals to humans. Surveys in the city of Niamey were conducted to monitor the presence of probable transmission of leptospirosis by rodents (Garba M. et al. 2014; and Dobigny G et al. 2015).

The general objective of this study is to confirm or not the transmission of animal leptospirosis to humans in the districts of Niamey. The specific objectives arising from the general objective are:

[1] To establish an estimate of the number of people affected in the neighborhoods constituting the sample.

[2] To Determine the socio-demographic characteristics of the populations of the pilot districts of Niamey.

[3] to Evaluate the impact of transmission risk factors.

\section{Materials and methods}

\section{Study design and study location}

A cross-sectional descriptive study was conducted from September 2020 to April 2021, and carried out in three different socio-demographic localities in Niamey where respondents were screened for to demonstrate transmission to humans.

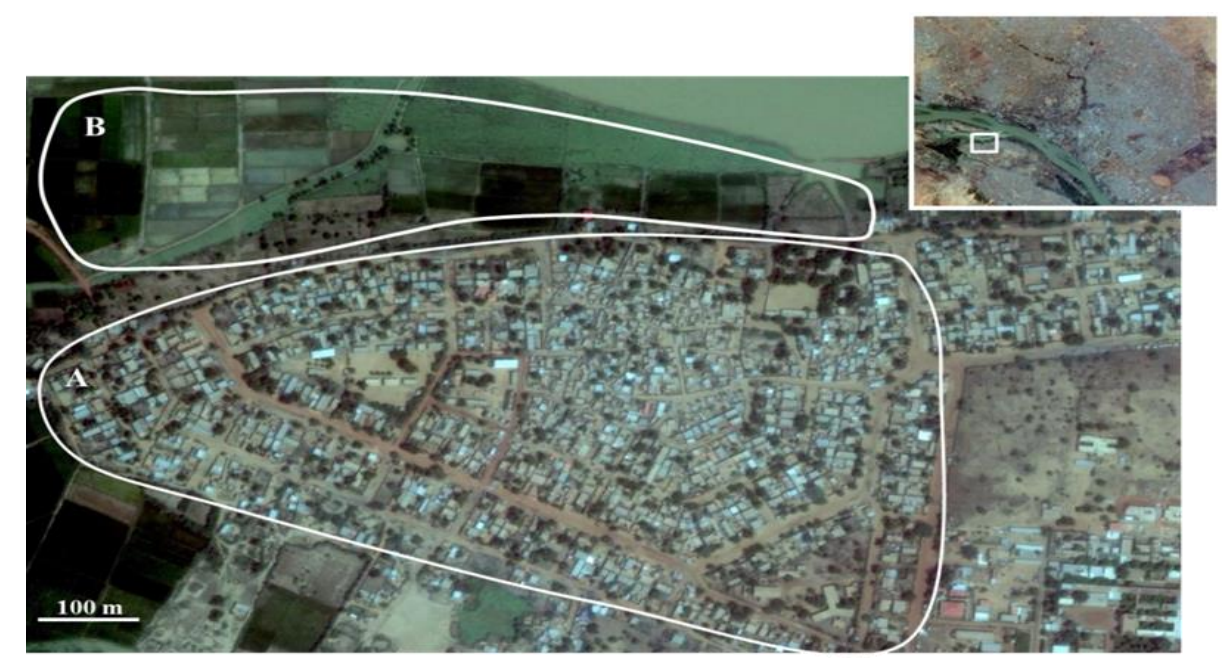

Fig.1. Sampling area within the Lamordé district. Insets A and B correspond respectively to residential areas and agricultural sites 


\section{A TAST}

Asian Journal of Applied Science and Technology (AJAST)

Volume 5, Issue 4, Pages 93-108, Oct-Dec 2021

The human sampling strategy consisted in targeting irrigated perimeters and a residential area in the Lamordé district (Fig.1) identified as high risk Leptospira (Fig.2), as well as a non-irrigated residential area in the Koira Tégui district. 402 consenting respondents were interviewed for socio-demographic data. Thus, in the Lamordé district, the residential area is home to many people working or going regularly to neighboring agricultural perimeters, which was verified by surveys carried out among people who volunteered to participate in the study.

The agricultural zone (inset B in Fig.1) immediately adjacent to the sampled residential area was also the subject of prospective studies with people who carry out regular activities there: of course, only people not residing in the area. zone A have been added to the sampling. As for the Koira Tégui neighborhood, the sampling was random and at the slaughterhouse level only workers from the animal slaughter market were sampled.

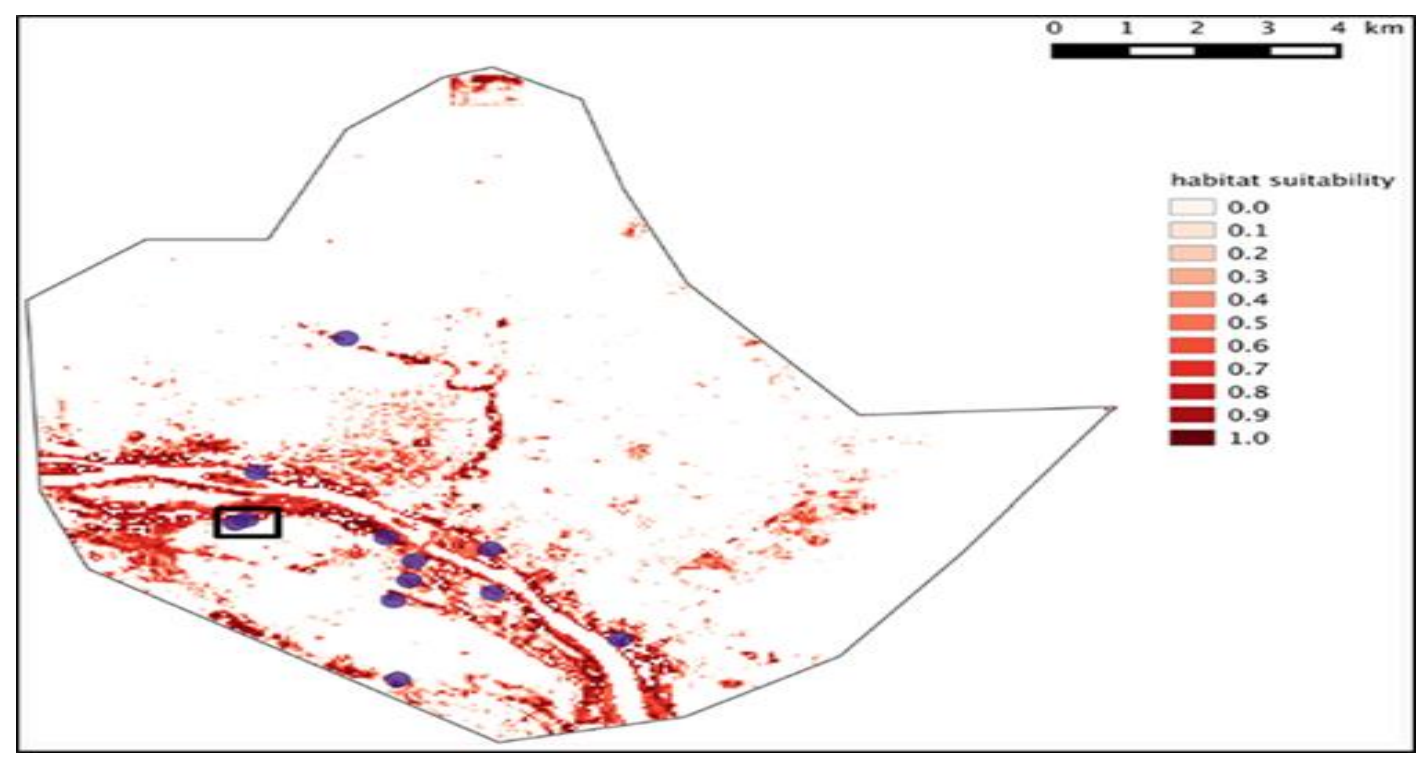

Fig.2. Leptospiral risk map in the city of Niamey (Dobigny et al 2015)

Each sampling campaign was accompanied by individual surveys in order to characterize:

(i) The recent medical history (consultations, appearance of fevers and other symptoms, etc.) of the people from whom the blood samples were taken,

(ii) Daily activities, in particular those possibly related to agricultural areas near the river (e.g. agricultural activities, dishes and laundry, swimming, etc.),

(iii) Personal experiences of the last episodes of river flooding or even flooding, and

(iv) Interactions (e.g direct observations, damage observed, implementation of rodent control) with intra- or peri-domiciliary rodents in their concessions or in their workplaces,

Likewise, a detailed description of the environment of all of each of the study areas was carried out in order to note the presence or absence of dumps, perennial ponds, etc.

\section{Ethics statement}

This study was submitted to the National Ethics Committee for approval. Likewise, before starting the sampling campaign, the municipal and traditional authorities in charge of each of the study areas, as well as the various heads 
of families were consulted. The objectives of this study were clearly explained to them in order to obtain their agreement. Each sample is taken on the basis of individual voluntary consent, and the consent of each participant is obtained in writing, thus subject to the commitment taken, personalized (i.e., serological status) and collective feedback (study post-awareness sessions) will be insured. In addition, participants diagnosed with leptospirosis will receive appropriate medical treatment.

\section{Sample collection and serological tests}

The following materials were used for data collection:

[1] clinical case inclusion form (this is a form containing information about the patient, the risk factors and the clinical signs);

[2] leptospirosis seroprevalence data collection sheet (a questionnaire that has five (5) parts: the first and second parts contain information on the investigator and the respondent, respectively; the third highlights the risk factors for exposure in the three weeks preceding the survey, the fourth provides information on a history of malaria, jaundice and meningitis; finally, the fifth part debriefing the biological examinations that will be carried out);

[3] Participant consent form: this form signed by the participant is an agreement according to which the latter has had an explanation on the nature of the study and that his participation is voluntary.

Thus, five milliliters of venous blood were drawn from the cubital fossa by medically qualified personnel and collected into a sterile plain tube. The serum was then separated by centrifugation and stored at $20{ }^{\circ} \mathrm{C}$ until further processing. All serum samples were tested for leptospiral antibodies using ELISA IgM/IgG test using SERION ELISA classic leptospiral IgM and IgG (Institute Virion-Serion GmbH, Warburg, Germany) [16]. The test procedure followed the manufacturer's protocol instructions (Partner diagnostics, ELISA, IgG, ELISA \& IgM, n.d.).

Leptospirosis being a fairly rare disease, the sera collected from the participants were grouped into groups of five to form serum pools of $25 \mu \mathrm{L}$ at a rate of $5 \mu \mathrm{L}$ per serum at random. These pools were homogenized using an electric stirrer. For the ELISA test, the procedure was first as follows (according to the instructions in the protocol): $1 \mu \mathrm{L}$ of serum from each sample is added to $100 \mu \mathrm{L}$ of dilution solution from the ELISA kit and then homogenized. Then, $100 \mu \mathrm{L}$ of diluted serum is taken and placed in each well of the plate; the first four wells are reserved respectively for the blank, the negative control serum and the two standard sera (positive control). Incubation in an oven for one hour at $37^{\circ} \mathrm{C}$ in a humid environment allows the conditions of the internal environment to be achieved in order to promote the binding between the antibodies of the serum and the antigens of the solid phase.

Once out of the oven, the plate is washed for the first time with $100 \mu \mathrm{L}$ of the kit's washing solution diluted (1:30) with sterile water. Each well is also washed three times in a row with the same quantity (100 $\mu \mathrm{L})$. At this stage, the wells having harbored a serum positive for leptospirosis bind the antibodies and the negative serum wells keep their basic structure. This is where the solution of serum conjugated to alkaline phosphatase is introduced into the wells at a rate of $100 \mu \mathrm{L}$ per well with the exception of the well which contained the blank and it is incubated again for 30 
minutes at $37^{\circ} \mathrm{C}$. in a humid environment. The antibodies of this conjugated serum are specific to anti-leptospirosis antibodies. A second wash under the same conditions as the first returns the negative serum wells to their basic structure and the positive serum wells bind the fixed anti-leptospirosis antibody antibodies associated with alkaline phosphatase; the leptospirosis antibodies having previously been attached to the solid phase antigens. A volume of $100 \mu \mathrm{L}$ of the developer substrate is then introduced into all the wells without exception followed by incubation at $37^{\circ} \mathrm{C}$ for 30 minutes. The substrate reacts with alkaline phosphatase to produce a change in color. On leaving the oven plate, $100 \mu \mathrm{L}$ of the stop solution is added to the wells to stop the reaction. The process is completed by reading the optical density at $405 \mathrm{~nm}$ on a spectrophotometer connected to a computer equipped with ELISA software. The result is measured photometrically by optical density (OD). The interpretation for the qualitative detection of leptospira IgM / IgG is as follows:

$\mathrm{IgM}<\mathrm{IU} / \mathrm{mL}=$ negative, $\mathrm{IgM} 15-19 \mathrm{IU} / \mathrm{mL}=$ borderline, $\mathrm{IgM} \geq 20 \mathrm{IU} / \mathrm{mL}=$ positive; $\mathrm{IgG}<10 \mathrm{IU} / \mathrm{mL}=$ negative, $\mathrm{IgG} 10-15 \mathrm{IU} / \mathrm{mL}=$ borderline, $\mathrm{IgG} \geq 15 \mathrm{IU} / \mathrm{mL}=$ positive.

All laboratory work was performed at CERMES Laboratory, Samples were considered seropositive with leptospiral antibodies if they were confirmed to have positive results.

\section{Data processing and Statistical Analysis}

\section{Study Variables}

These are socio-demographic variables, risk variables, and explanatory variables. Sociodemographic variablesthese variables are: age, sex, type of dwelling and occupation; they have been used to identify the most vulnerable segments of the population.

\section{Risk variables}

These are the most prominent risk factors in sick subjects. These are among others:

(1) Environment at risk.

(2) House on the edge of a watercourse.

(3) Presence of animals in the concession.

(4) Poor waste management.

\section{Clinical variables}

Clinical history is reviewed, in particular on malaria, jaundice and meningitis, thus making it possible to assess the impact of the comorbidities of the various forms of leptospirosis.

\section{Criterion of inclusion and non-inclusion}

\section{Inclusion criteria}

(1) People over 18 living in the concessions of the Lamordé and Koira Tégui districts.

(2) Workers in the Niamey cattle slaughter market. 


\section{Non-inclusion criteria}

(1) Workers not working in the selected premises.

(2) Workers who were unhealthy with a history of fever and those who were not present on the day of sample collection.

\section{Statistical Analysis}

Where appropriate, statistical analysis will be performed using the test of variance (one way ANOVA) using Epi Info software. Significant difference $(\mathrm{P}<0.05)$ amid means will be determined by Kruskal-Wallis test (John 2003).

\section{Results}

Of the four hundred and two (402) respondents, there are 124 male and 278 female. It should also be noted that of these respondents 80 work in animal slaughterhouses. The average age group is estimated at: 34.67 years for women and 37.23 years for men.

\section{Socio-demographic Characteristics of the population}

The sample population consists mainly of women (69.15\%). However, we recorded 9 positive cases among men and 2 cases among women.

\section{Gender Study}

Table 1. Population gender study

\begin{tabular}{|c|c|c|c|c|c|}
\hline Sex & Effective & Prevalence & $\begin{array}{c}\text { Number of } \\
\text { cases }\end{array}$ & Prevalence & $\begin{array}{c}\text { Number of cases } \\
\text { per age groups }\end{array}$ \\
\hline Masculine & 124 & $30.85 \%$ & 9 & $7.26 \%$ & $22-52$ years \\
\hline Feminine & 278 & $69.15 \%$ & 2 & $0.72 \%$ & $23-75$ years \\
\hline
\end{tabular}

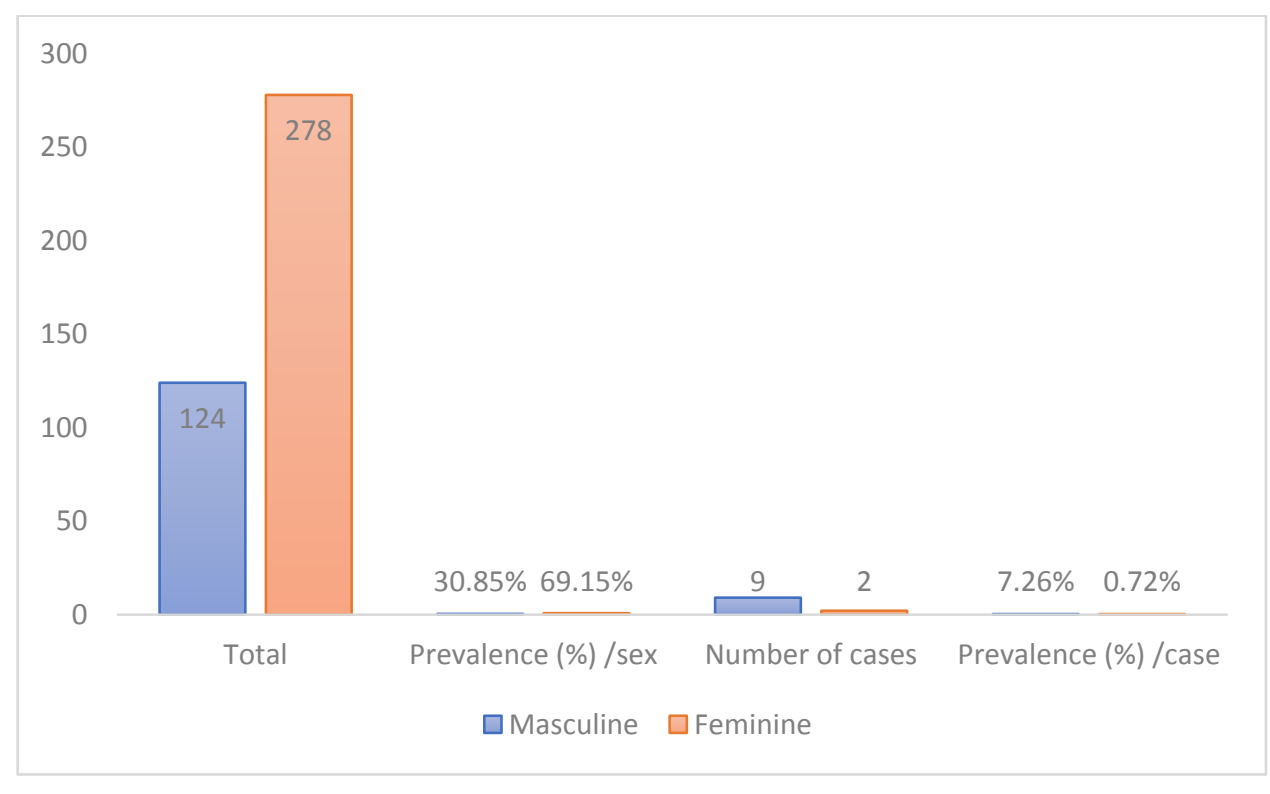

Fig.3. Cross-graph of the distribution of cases by sex 


\section{AJA5T}

Asian Journal of Applied Science and Technology (AJAST)

Volume 5, Issue 4, Pages 93-108, Oct-Dec 2021

Men are more affected by leptospirosis than women with a prevalence ten times higher than that of women. As for the distribution by age, we see that all age groups are affected (from the youngest 22 to the oldest 75 ).

Table 2. Summary of Results

\begin{tabular}{|c|c|c|c|c|}
\hline Site & $\begin{array}{c}\text { Number of } \\
\text { respondents }\end{array}$ & Positive case & Prevalence/site & $\begin{array}{c}\text { Total } \\
\text { Prevalence }\end{array}$ \\
\hline Slaughterhouse & 82 & 8 & $9,75 \%$ & $2 \%$ \\
\hline Lamordé & 100 & 2 & $2 \%$ & $0,5 \%$ \\
\hline Koira Tégui & 220 & 1 & $0,45 \%$ & $0,25 \%$ \\
\hline Total & 402 & 11 & - & $2,75 \%$ \\
\hline
\end{tabular}

According to Table 1 which led to Table 2 (summary) and Fig.4, it can be seen that the animal slaughterhouse alone has $2 \%$ of the total prevalence of $2.75 \%$ of respondents inflicted with leptospirosis. It should also be noted that this area has the highest prevalence although the number of people sampled is relatively low compared to other neighborhoods

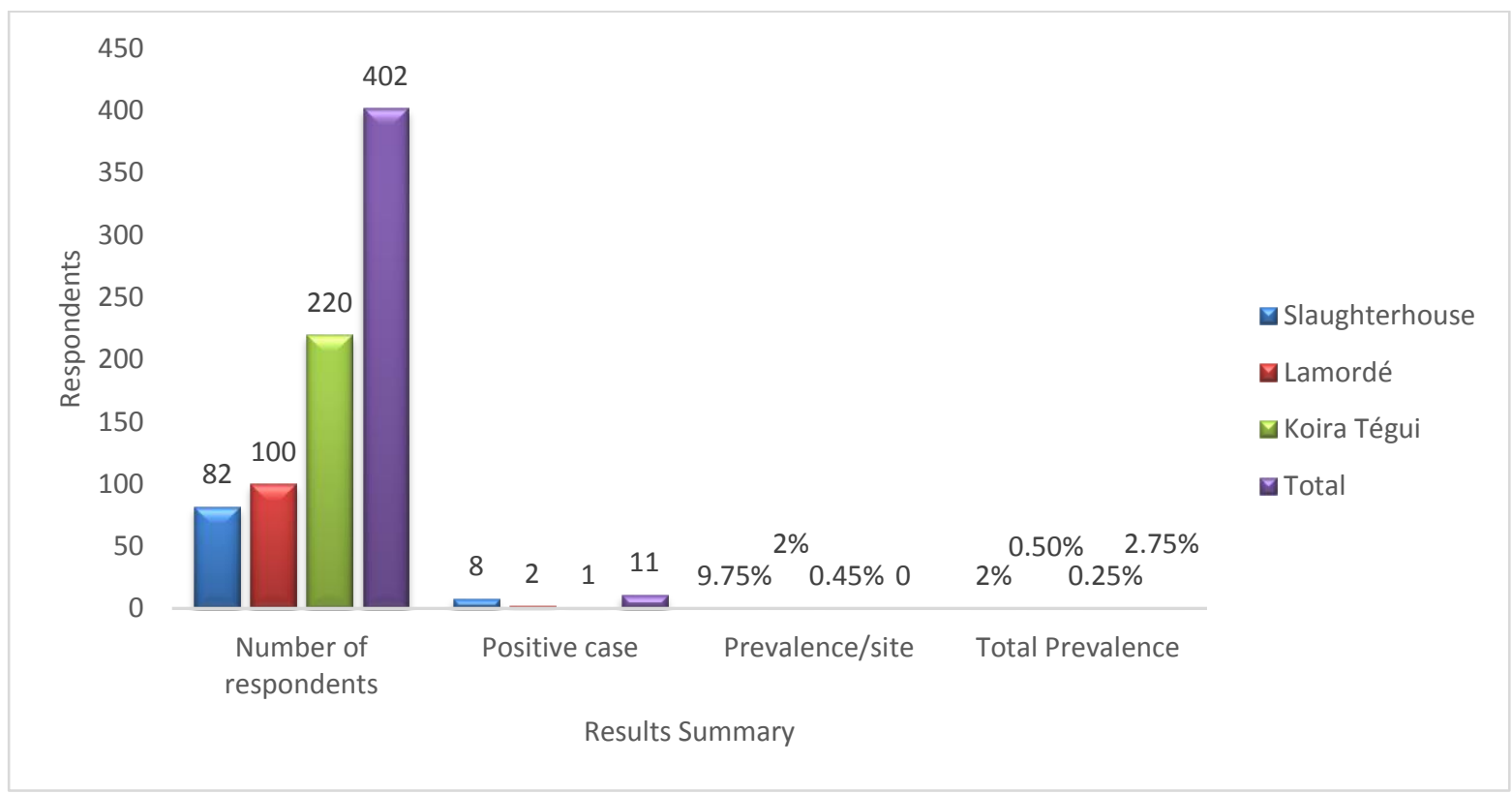

Fig.4. Summary

\section{Type of Dwelling or Habitat}

Table 3. Distribution of the population according to the type of habitat or dwelling

\begin{tabular}{|c|c|c|c|c|}
\hline $\begin{array}{c}\text { Type of } \\
\text { Dwelling }\end{array}$ & Frequency & Percentage & Number de case & Prevalence \\
\hline Cement & 160 & $39.8 \%$ & 8 & $5 \%$ \\
\hline Aluminum & 3 & $0.7 \%$ & 0 & $0 \%$ \\
\hline
\end{tabular}


Volume 5, Issue 4, Pages 93-108, Oct-Dec 2021

\begin{tabular}{|c|c|c|c|c|}
\hline $\begin{array}{c}\text { Sheet roof } \\
\text { (ASR) }\end{array}$ & 198 & $49.3 \%$ & 3 & $1.51 \%$ \\
\hline $\begin{array}{c}\text { Compressed } \\
\text { earth block } \\
\text { (mud) (CEB) }\end{array}$ & 1 & $0.2 \%$ & 0 & $0 \%$ \\
\hline $\begin{array}{c}\text { Compressed } \\
\text { earth block+ } \\
\text { straw (CEG+St) }\end{array}$ & 38 & $9.5 \%$ & 0 & $0 \%$ \\
\hline $\begin{array}{c}\text { Dwelling in } \\
\text { Straw (Dwel.St) }\end{array}$ & 2 & $0.5 \%$ & 0 & $0 \%$ \\
\hline Others & 402 & $100,0 \%$ & 11 & \\
\hline Total & & & 0 & \\
\hline
\end{tabular}

The most common habitats or dwellings in the study areas are of compressed earth block (or mud commonly called banco) $(49.3 \%)$ and of cement type habitat (39.8\%).

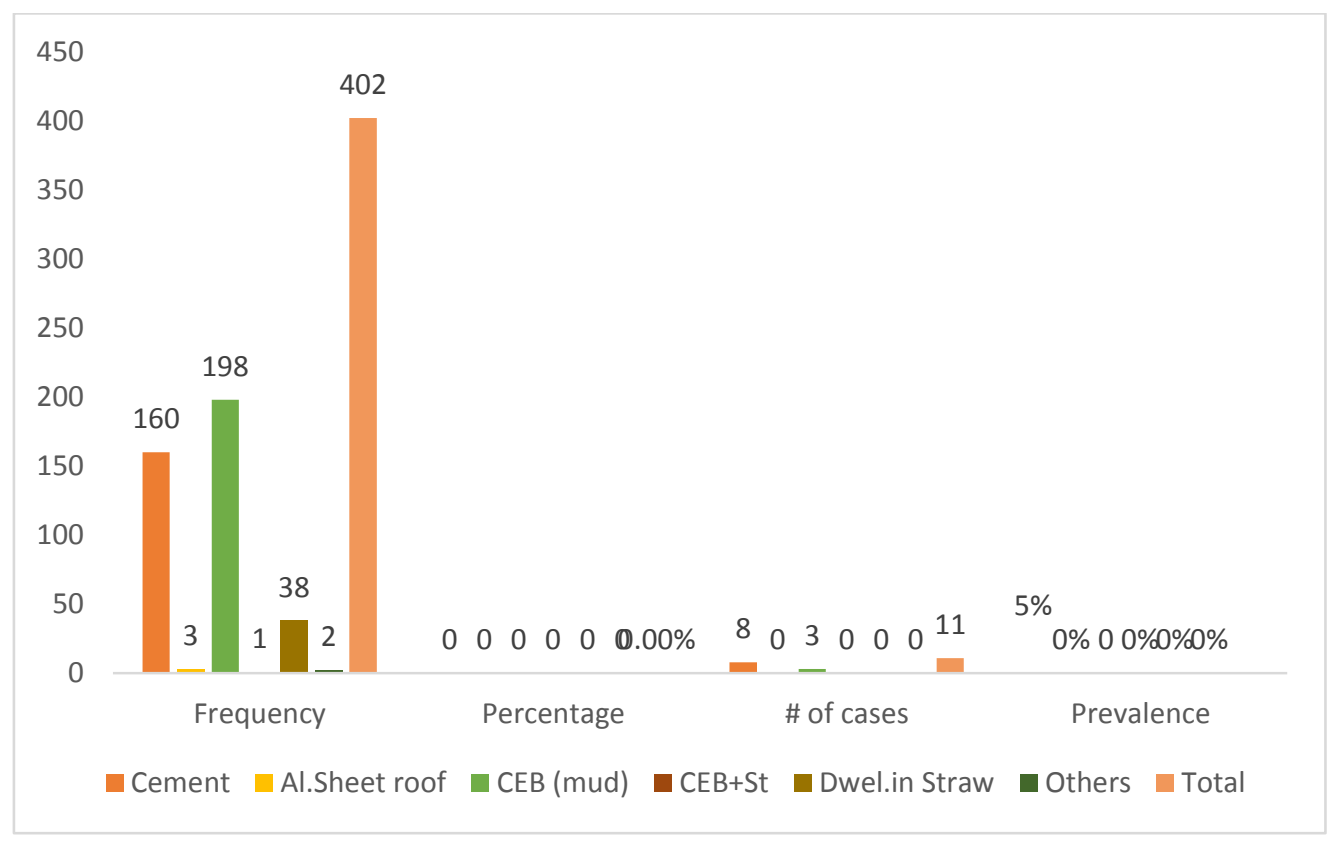

Fig.5. Cross-graph of the distribution of the number of cases according to the type of habitat or dwelling

Almost half of the sample population lives in "compressed earth block" type dwellings commonly called "banco". However, $72 \%$ of leptospirosis cases are people living in cement houses type and $28 \%$ of the dwellings or habitats are in cement. No statistically significant association was found between living condition and been inflicted with leptospirosis: $\chi 2=0,9345 ;$ P-value $=0,3337$; IC: $95 \%$ ). 


\section{Occupations}

Table 4. Distribution of the population by occupation

\begin{tabular}{|c|c|c|c|c|}
\hline Occupation & Frequency & Percent & Number of cases & Prevalence \\
\hline Farmer & 12 & $3.0 \%$ & 0 & $0 \%$ \\
\hline Market gardener & 9 & $2.2 \%$ & 0 & $0 \%$ \\
\hline Butcher & 70 & $17.4 \%$ & 7 & $10 \%$ \\
\hline Others & 311 & $77.4 \%$ & 4 & $1.29 \%$ \\
\hline Total & 402 & $100,0 \%$ & 11 & - \\
\hline
\end{tabular}

More than $77 \%$ of the population have a professional activity other than those identified as at risk. In this segment of this population, we have identified 4 cases with a prevalence of $1.29 \%$, and the remaining cases are from the butcher profession.

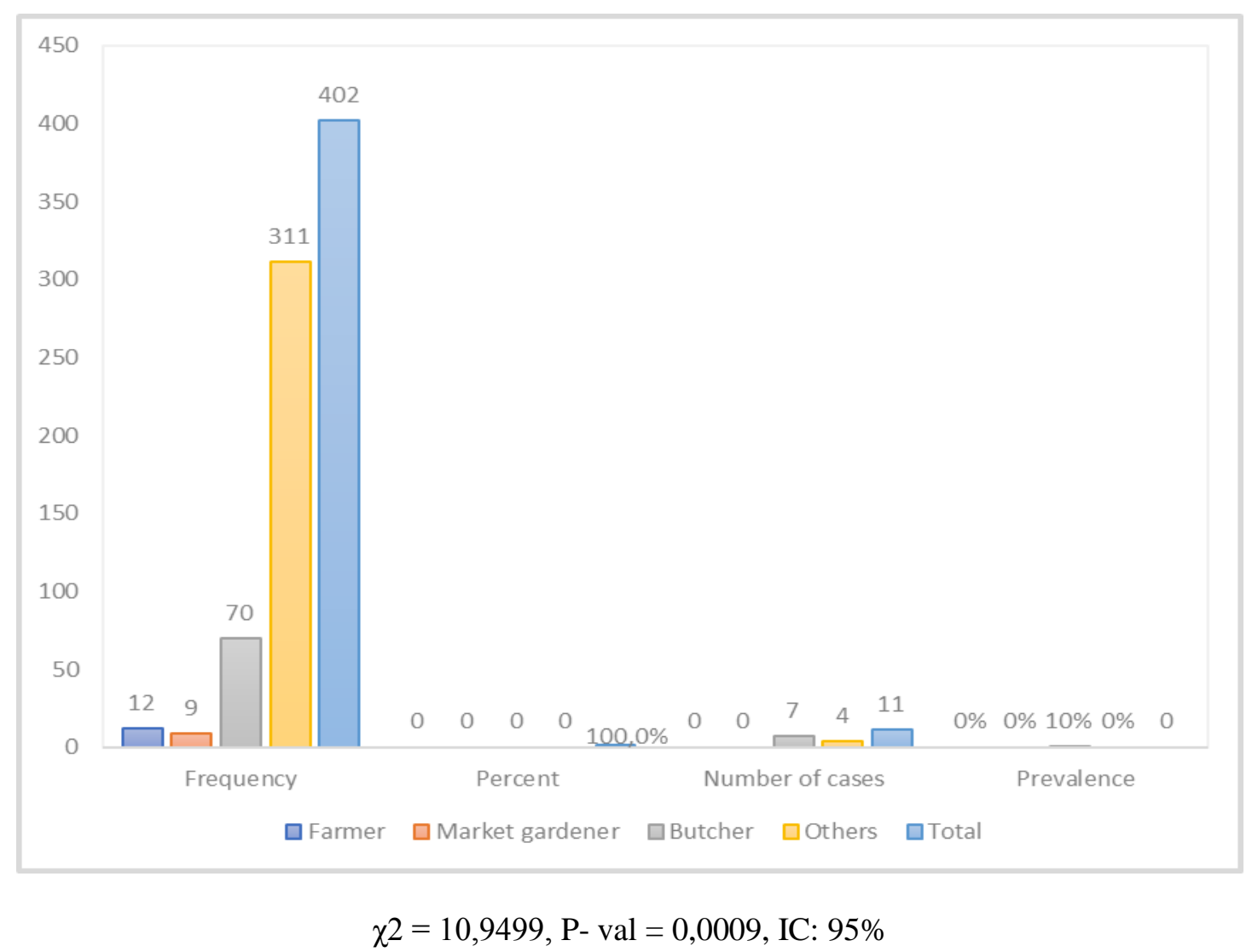

Fig.6. Cross-graph of the distribution of cases according to Occupation

Among the occupations listed, the most at risk is that of " butchers or those working in the slaughterhouse " with a prevalence of $10 \%$ (seven out of eleven people who have been inflicted with leptospirosis are butchers). Our result showed a statistically significant relationship between occupation and likelihood of been inflicted with leptospirosis. 


\section{Risks Study}

The population of this study is a population relatively exposed to the main risk factors for leptospirosis. Thus, more than $87 \%$ of the population lives in an environment containing rodents which are the main reserve of leptospira. Out of 352 people exposed, only 6 tested positive for leptospirosis, for a prevalence of $1.70 \%$. In addition, swimming is the risk factor with the high

Table 5. Study of risk factors

\begin{tabular}{|c|c|c|c|c|c|}
\hline Risk Factors & Exposed & Non exposed & $\begin{array}{c}\text { Prevalence } \\
\text { of exposed }\end{array}$ & $\begin{array}{c}\text { Exposed } \\
\text { cases }\end{array}$ & Prevalence \\
\hline Contact with Animals & 193 & 209 & $48 \%$ & 8 & $4,15 \%$ \\
\hline Swimming & 52 & 350 & $12,9 \%$ & 4 & $7,70 \%$ \\
\hline Dwelling near puddles & 155 & 247 & $38,6 \%$ & 3 & $1,94 \%$ \\
\hline Presence of rodents & 352 & 50 & $87,6 \%$ & 6 & $1,70 \%$ \\
\hline
\end{tabular}

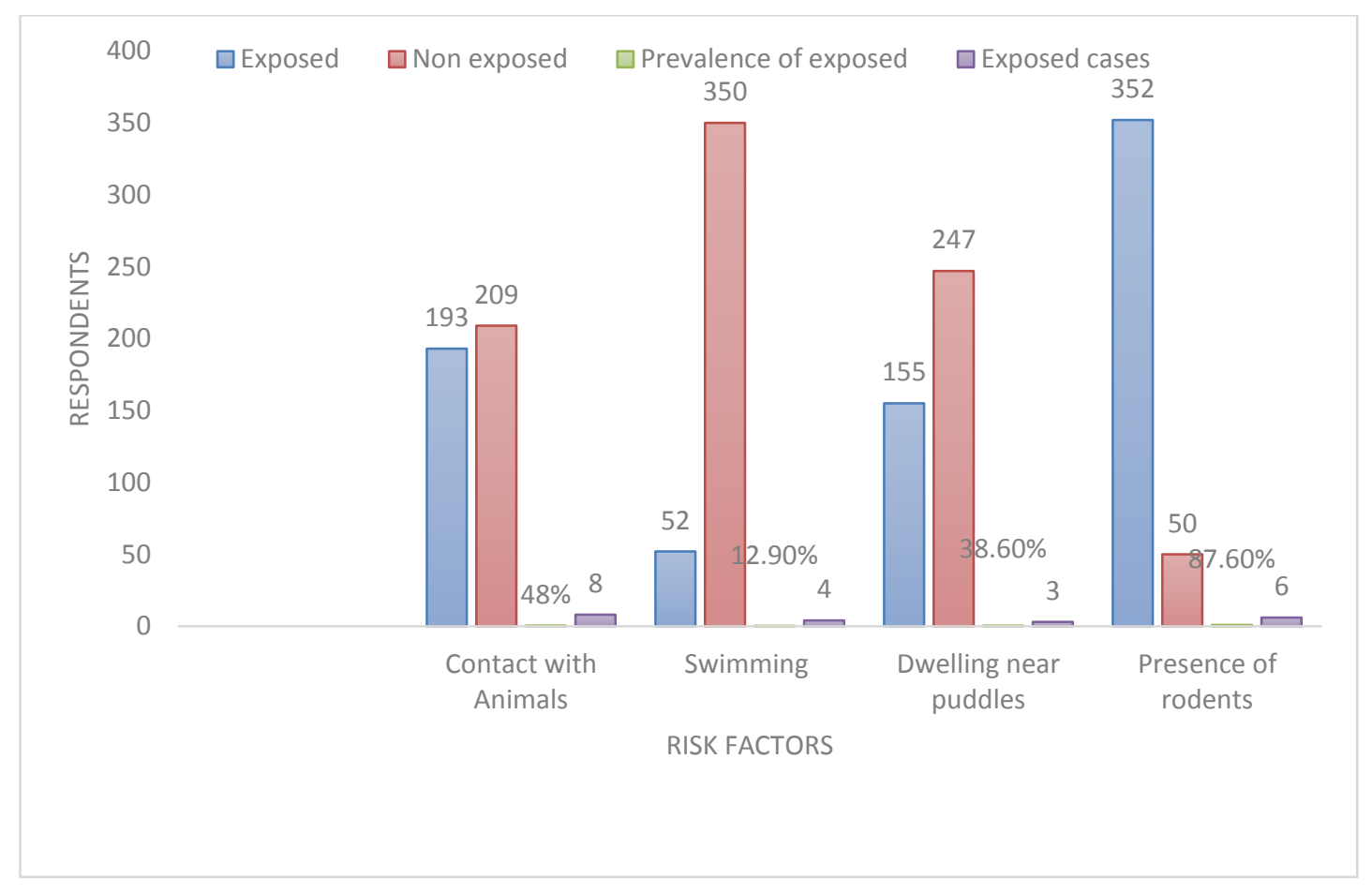

Fig.7. Cross-graph of the distribution of cases according to risk factors
$\chi^{2}$
5,4982
2,7613
0,6064
11,2919
P- val
$(\mathrm{P}<0.05)$
0,0190
0,0966
0,4362
0,0008
IC: $95 \%$

The respondents for this study are a population relatively exposed to the main risk factors for leptospirosis. Thus, more than $87 \%$ of the population lives in an environment containing rodents which are the main reserve of leptospira. Out of 352 people exposed to rodents, 6 tested positive for leptospirosis, for a prevalence of $1.70 \%$. 
Swimming, another risk factor, has the highest prevalence with $7.70 \%$.

It should also be noted that the number of exposed cases is not cumulative because the cases are exposed to several risk factors at the same time.

\section{Clinical Study}

Table 6. Clinical history of participant

\begin{tabular}{|c|c|c|c|c|}
\hline Antecedents & Frequency & Prevalence & Number of cases & Prevalence \\
\hline Malaria & 222 & $55,2 \%$ & 3 & $1,35 \%$ \\
\hline Meningitis & 4 & $1 \%$ & 0 & $0 \%$ \\
\hline
\end{tabular}

About $55 \%$ of the population has a history of malaria and $1 \%$ for meningitis. It should also be noted that $27 \%$ of leptospirosis inflicted respondents have a history of malaria.

\section{Discussions}

Leptospirosis is present in all regions of the world, making it the second most common zoonosis after Covid-2019. The work by Costa et al. 2015 reported annual incidence rates of 1 million cases (95\% CI: 434,000 -1,750,000) with an estimated mortality of around 60,000 patients (95\% CI: 23,800-95,900) worldwide. The death rate linked to leptospirosis is between $5 \%$ and $20 \%$ of cases depending on country.

This study, carried out on a population of 402 people in neighborhoods of variable risk has detected 11 positive cases for leptospirosis by the ELISA test, but this number could be higher if the ELISA test were supplemented with the MAT test as is done in standard norms. This study, first confirms the transmission of animal leptospirosis to humans in the districts of Niamey, and second, gives an idea of the degree of the transmission. Furthermore, the sampling method does not allow to make an extrapolation on the general population of the concerned areas.

The distribution of positive cases by sex confirms a trend according to which professional activity or occupation has a major impact as a risk factor. Study by Peslerbe 1992, reported that the professional activities at risk are those that put workers in contact with fresh water, damp soil contaminated by rat urine such: sewer workers, personnel of wastewater treatment plants, maintenance personnel of banks and waterways, fish farmers. Professionals in contact with infected animals (dogs, cattle, foxes, wild boars) alive or dead, or with their contaminated environments are also concerned. These professionals are among others: veterinarians, slaughterhouse or rendering workers, veterinary laboratory staff (INRS 2009). In our case study, the male respondents are mostly butchers (more than $72 \%$ of positive cases), an activity which forces several factors of leptospirosis, making the male sex to be more represented among carriers of leptospira. As for the factors that influence the risk of contracting the disease, it seems that men are more predisposed to exposure to leptospira because an urban to peri-urban living environment is also a contributing factor in connection with urbanization, growth not always controlled and the unsanitary conditions that accompany it (Romich 2008; A. Diquélou \& R. Lavoué 2017). Overall, for humans, and particularly in developed countries, two types of exposure factors can be distinguished: in $75 \%$ of cases, they are linked to an 
aquatic leisure activity; and in 25\% of cases to a professional activity (Pilly and College of Infectious and Tropical Diseases University 2018).

In addition, it should be noted that professional activity has a real implication in the exposure of populations to leptospirosis. In our case study, it was found that the activity of 'butcher' has a greater prevalence compared to other activities. This is because the working environment for this activity is the least healthy and the most frequented by rodents. These workers are subject to a convergence of risk factors in their area of activity and their area of residence. Furthermore, the modern animal slaughterhouse of the city of Niamey is an area of remarkable hygiene deficiency. Apart from the presence of rodents, animals slaughtered at the site are also likely to be vectors of leptospira.

With regard to the type of habitat, it emerges through this study that it is not in itself a risk of leptospirosis but rather the environment, in which men live, constitutes a factor of exposure to factors actual risk of the disease. As with other zoonoses, the epidemiology is closely linked to ecosystems: presence of fresh water, favorable climatic conditions. Survival in the external environment can last from several days to several weeks depending on whether these conditions are met or not (INRS 2009).

For a pilot study of this nature and in the context of this zoonosis, our results provide a revealing basis for the level of exposure of the sampled populations to different risk factors, and all the risk factors have a fairly high number of people exposed for a sample of such size. At first glance, the presence of rodents (the most important vectors and reservoirs of leptospira) seems to be the most influential risk factor. In developing countries, high rates of infection have also been found in cities, mainly in deprived urban areas which generally show unsanitary conditions and where rodents are numerous (United Nations 2014 \& Ganoza et al. 2006). But living in an environment frequented by rodents is not de facto a real risk because these rodents would have to be proven carriers of leptospira for the risk to be effective. Indeed, Rattus rattus and M. natalensis are by far the most abundant rat species found in Niamey (Garba et al. 2014). Yet, of the 450 specimens of these two species that were tested here (, Rattus rattus and M. natalensis), none tested positive for Leptospira. On the contrary, only specimens of Arvicanthis niloticus and Cricetomys gambianus, all trapped in urban market gardens, were detected as Leptospira carriers. Leptospira seem to be absent from the city of Niamey where usually Leptospira reservoir rodent species (namely R. Rattus and M. Natalensis) are still abundant (Dobigny et al. 2015).

As for the real influence of risk factors, bathing is the most severe, very probably taking into account on the one hand that these bathing waters are soiled by leptospira and on the other hand by the optimal conditions for leptospira growth in these last. The results of our study show that more than $36 \%$ of positive cases are exposed to swimming, which is one of the risk factors.

The population of this study is a population fairly in contact with animals (48\%), the latter of the bovine type, and sheep are major vectors of leptospira with the potential to considerably increase the risk of infection. Especially when we refer to the way in which this contact is made, the risk is all the greatest, whether at the breeding or slaughtering level, the barrier measures against infections of this kind are clearly lacking in the appointment. Furthermore, this study reveals that 8 individuals tested positive for leptospirosis are in contact with animals. 
Another important fact to underline is the presence of puddles near dwellings or habitats in Niamey neighborhoods, especially in the rainy season. During this season, the districts of Niamey are the scene of flooding and stagnating water. These waters drain the leptospira secreted by the carrier animals which are constantly in free circulation in these quarters. These puddles can pose a risk for both the healthy animals roaming the water in search of food and to humans who somehow come into contact with the wastewater.

In tropical areas, contact with contaminated water following episodes of heavy rains and flooding is considered a major risk of exposure to the pathogens Leptospira spp. (Lau 2010).

In addition, there are variations in the sensitivity of the species to leptospira. We can thus distinguish between vector animals (for example mice), in which the infection is asymptomatic and which will simply promote the active multiplication of the bacteria and their secretion into the environment. These host species can trigger more or less severe clinical forms depending on the virulence of the infecting serovar and certain individual sensitivity factors (age, immunity, etc.). Finally, there are also accidental hosts, such as humans for example, for whom all clinical forms are possible (Andre-Fontaine 2012).

A protean presenting disease, leptospirosis is classically described as being able to induce a range of manifestations ranging from a simple, spontaneously resolving flu-like syndrome to multi-visceral failure with fatal risk (P. N. Levett 2001; Bharti et al. 2003). This makes the diagnosis all the more complicated: it is estimated that many cases of leptospirosis go undiagnosed and mistaken for another type of infection (Raffray 2017).

After an average incubation phase of 7-10 days (extremes of 2 to 20 days), the initial symptoms mainly include fever and myalgia, with a less frequency of headache, abdominal pain, conjunctival suffusion and a possible rash. evanescent skin.

The clinical results of our study reveal $55.20 \%$ of subjects have a history of malaria, and $27 \%$ of which are inflicted with leptospirosis.

Our data do not support the conclusion that the observation of clinical signs in these subjects and the episodes of malaria (a disease with symptoms similar to leptospirosis) are synonymous with a severe form of leptospirosis. This could be the result of comorbidity, especially due to the fact that malaria can be an opportunistic disease. In addition, the results of the study by Dobigny et al 2015 showed that leptospira transmitted by rodents in Niamey belong to serovars (L. kirschneri) which had not been described until then.

\section{Conclusions}

Leptospirosis is a disease that is transmitted from animals to people. It has not very specific manifestations and is unknown. Its diagnosis is hardly operational in our territory and there is a serious lack of local data. It is clear that various risk factors increase the likelihood for an exposed individual to be inflicted with leptospirosis. Several studies showed evidence of leptospiral co-infections with unrelated diseases such dengue and malaria highlighting the culminating severity of leptospirosis, however, our results did not find such correlating evidence although the respondents tested positive of leptospirosis in this study have antecedent to malaria. Our study can allow us to confirm that there is a transmission of leptospira from animals to humans and the population of the neighborhoods 


\section{AJAST}

Asian Journal of Applied Science and Technology (AJAST)

Volume 5, Issue 4, Pages 93-108, Oct-Dec 2021

according to the risk factors to which they are exposed do not have the same level of vulnerability. Although methodological sampling limits do not allow to underline the real impact of the different factors, the obtained results show the future challenges that may face any research on leptospirosis.

With a population relatively at risk for an undiagnosed disease, caution must be exercised while undertaking a research program that look at a better understanding of the virulence and pathology mechanisms of the disease for more effective prevention and management. In the meantime, we believe that efforts will or would be taken to at least get the minds of vulnerable populations out of ignorance of the danger that runs around.

\section{Acknowledgements}

This work was supported by FARSIT and the Ministry of Health of Niger. The CERMES Units of Bactériology, Virology and Epidemiology provided very helpful technical support.

\section{Declarations}

\section{Competing Interests Statement}

The authors declare no competing financial, professional and personal interests.

\section{Consent for publication}

Authors declare that they consented for the publication of this research work.

\section{Ethical Approval}

This study was submitted to the National Ethics Committee for approval. Likewise, before starting the sampling campaign, the municipal and traditional authorities in charge of each of the study areas, as well as the various heads of families were consulted. The objectives of this study were clearly explained to them in order to obtain their agreement. Each sample is taken on the basis of individual voluntary consent, and the consent of each participant is obtained in writing, thus subject to the commitment taken, personalized (i.e., serological status) and collective feedback (study post-awareness sessions) will be insured. In addition, participants diagnosed with leptospirosis will receive appropriate medical treatment.

\section{References}

Picardeau M; Leptospirosis: Updating the Global Picture of an Emerging Neglected Disease. PLOS Neglected Tropical Diseases; 2015; 9(9): e0004039. Doi: 10.1371/ journal. pntd.0004039.

Paul N. Levett:, Leptospirosis, Clinical Microbiology Reviews, Apr.2001, pp. 296-326.

Morgan M; la leptospirose, étude comparative de la pathologie et des méthodes de diagnostic chez l'homme et l'animal, thèse de Doctorat; Campus vétérinaire de Lyon; pp.19; 25; 2019; [en ligne] disponible sur https://www.google.com/url? sa=t \&source = web \& rct=j \&url= http://www2. vetagro-sup.fr /bib/ fondoc/thsout/ dl.php\% 3Ffile\%3 D2019 lyon105.pdf \&ved =2ahUKEwjAtZr2 g4vxAhWE5OAKHax2 APwQFjABegQIBBAC usg=AOvVaw3xDHyoSdewDMg4Aw37oTI9. 
Cameron C. E., Leptospiral structure, physiology, and metabolism, Curr. Top. Microbiol. Immunol., 2015.

Liegeon G, Delory T, and Picardeau M; Antibiotic susceptibilities of livestock isolates of leptospira, Int. J. Antimicrob. Agents, vol. 51, no. 5, pp. 693-699, May 2018.

WHO: Report of the Second Meeting of the Leptospirosis Burden Epidemiology Reference Group. 2011, pp.1-37. Costa, Federico, José E. Hagan, Juan Calcagno, Michael Kane, Paul Torgerson, Martha S. Martinez Silveira, Claudia Stein, Bernadette Abela-Ridder, et Albert I. Ko. 2015. Global Morbidity and Mortality of Leptospirosis: A Systematic Review. PLoS Neglected Tropical Diseases 9(9): e0003898. Doi : 10.1371/journal.pntd.0003898.

Raffray L, Immunopathologie de la leptospirose humaine: exploration de la réponse immunitaire innée 2017; [en ligne] disponible sur https://www.theses.fr/2017LARE0006.

De Vries S. G, Visser B. J, Nagel I. M, Goris M. GA, Hartskeerl R. A, Grobusch M. P; Leptospirosis in Sub-Saharan Africa: a systematic review. Int. J. Infect. Dis. 2014; 28: 47-64; [en ligne] disponible sur https://www. sciencedirect.com/science/article/pii/S1201971214015732.

Kathryn J. Allan, Holly M. Biggs, Jo E. B. Halliday, Rudovick R. Kazwala, Venance P. Maro, Sarah Cleaveland, and John A. Crump: Epidemiology of Leptospirosis in Africa: A Systematic Review of a Neglected Zoonosis and a Paradigm for 'One Health' in Africa. PLoS Negl Trop Dis. 2015 Sep; 9(9): e0003899. Published online 2015 Sep 14. doi: 10.1371/journal.pntd.0003899.

Garba M, Dalecky A, Kadaouré I, Kane M, Hima K, Véran S, Gagaré S, Gauthier P, Tatard C, Rossi JP \& Dobigny G. Spatial segregation between invasive and native commensal rodents in an urban environment: a case study in Niamey, Niger. PLoS ONE. 2014; 9: e110666. doi: 10.1371/journal.pone.0110666 PMID: 25379785.

Dobigny G, Garba M, Tatard C, Loiseau A, Galan M, Kadaoure I, Rossi JP, Picardeau M, Bertherat E. Urban gardening and leptospirosis in arid zones. PLOS Neg. Trop. Dis. 2015 ; DOI:10.1371/ journal.pntd.0004097 ; [en ligne] disponible sur https://journals.plos.org /plosntds /article? id=10.1371/journal.pntd.0004097.

John D. Spurrier, On the null distribution of the Kruskal-Wallis statistic, Journal of Nonparametric Statistics, vol. 15, no 6, 1er décembre 2003, pp. 685-691.

Peslebre F, André Fontaine G, Ganière JP, Prévalence sérologique de la leptospirose chez le personnel d'entretien des voies navigables de la Loire-Atlantique et de la Maine-et-Loire; Arch Mal Prof; 1992; 53(I): pp.54-56.

INRS; Leptospirose et milieu professionnel; Doc. pour le médecin de travail, vol. 4; no. 120; 2009, pp.485-487.

United Nations-Habitat. The state of African cities in 2014: re-imagining sustainable urban transitions. UN-Habitat, States of cities reports; 2014.

Ganoza CA, Matthias MA, Collins-Richards D, Brouwer KC, Cunningham CB, Segura ER, Gilma RH, Gotuzzo E \& Vinetz JM; Determining risk of severe leptospirosis by molecular analysis of environmental surface waters for pathogenic Leptospira. PLoS Med. 2006; 3: e308. PMID: 16933963. 
Romich J; Understanding zoonotic diseases, 2008; [en ligne] disponible sur https://www.worldcat.org/title/ understanding-zoonotic-diseases/oclc/153598483\&ved=2ahUKEwioh Y6su4rxAhXqBGMBHejm CeMQFjAHeg QIFRAC\& usg =AOvVaw05dWgK8T9koqIXocdR8PSo.

Diquélou A, Lavoué R, Leptospirose: actualités cliniques, diagnostiques et protocoles vaccinaux, La dépêche Tech., pp. 7-10, 2017.

Pilly E and Collège des universitaires de maladies infectieuses et tropicales, Maladies infectieuses et tropicales, 26ème édition. 2018; [en ligne] disponible sur https://www.google.com/url? sa=t\& source=web\&rct=j\&url=https: //www.amazon.fr/Pilly-Maladies-infectieuses tropicales/dp/.

Lau CL, Smythe LD, Craig SB \& Weinstein P. Climate change, flooding, urbanization and leptospirosis: fueling the fire? Trans Roy Soc Trop Med Hyg. 2010; 104: 631-638. doi: 10.1016/j.trstmh.2010.07. 002 PMID: 20813388. Andre-Fontaine G, Zoonoses. Tome 2 : maladies bactériennes, Bull. Group. Tech. Vétérinaire, pp. 127-130, 2012. Ajay R Bharti, Jarlath E Nally, Jessica N Ricaldi, Michael A Matthias, Monica M Diaz, Michael A Lovett, Paul N Levett, Robert H Gilman, Michael R Willig, Eduardo Gotuzzo, and Joseph M Vinetz, Leptospirosis: a zoonotic disease of global, Lancet Infect Dis 2003; 3: pp. 757-71. 